\title{
Critical Discourse Analysis and Metaphor: Toward a Theoretical Framework ${ }^{1}$
}

\author{
Christopher Hart \\ University of Hertfordshire \\ c.j.hart@herts.ac.uk
}

\begin{abstract}
Critical Discourse Analysis (CDA) explores the role of discourse structures in constituting social inequality. Metaphorical structure, however, has received relatively little attention in explicit CDA. The paper aims to redress this by developing a coherent theoretical framework for CDA and metaphor. This framework adopts conceptual blending theory over conceptual metaphor theory, where the latter is perceived to be incompatible with CDA. The framework is applied in a CDA of metaphors for nation and immigration in the British National Party's 2005 general election manifesto.
\end{abstract}

Keywords: critical discourse analysis; social cognition; metaphor; conceptual blending theory; immigration discourse.

\footnotetext{
${ }^{1}$ Accepted July 2007. Critical Discourse Studies.
} 


\section{Introduction}

For mainstream CDA, as Chilton (2005a: 21) states, "Halliday's systemic functional grammar has supposedly provided the toolkit for deconstructing the socially-constructed (and thus linguistically constructed) machinery of power". Properties of discourse to have received much attention include, for example, agentless passive constructions and nominalisations (Fairclough 1989; Fowler 1991; Fowler et al. 1979; Kress 1985; Kress and Hodge 1979). Argumentation theory has also been drawn upon in CDA, highlighting various topoi, or standard arguments, which appear in racist discourse (van Dijk 2000; Wodak and Sedlak 2000). Metaphor, on the other hand, has been largely neglected in mainstream CDA (cf. Chilton 2005a). However, as Charteris-Black (2004: 28) states, "metaphor is . . central to critical discourse analysis since it is concerned with forming a coherent view of reality". Where CDA (and Critical Linguistics in particular) has been concerned with ideological and mystifacatory structures of discourse, metaphor is just such a structure. Hodge and Kress (1993: 15) contend that ideology involves "a systematically organised presentation of reality". Metaphors are ideological, then, in so far as they "define in significant part what one takes as reality" (Chilton and Lakoff 1995: 56). According to Chilton (1996: 74), metaphors "can contribute to a situation where they privilege one understanding of reality over others". Metaphors also play an important role with regard to both the interpersonal and the ideational function of language described by Halliday (1985).

To analyse meaning reproduced through any discourse property requires a cognitive approach. As Chilton (2005a: 23) states, discourse is

produced and interpreted by human individuals interacting with one another...If language use (discourse) is, as the tenets of CDA assert, connected to the 'construction' of knowledge about social objects, identities, processes, etc., then that construction can only be taking place in the minds of (interacting) individuals.

In the sociocognitive approach of course, van Dijk has addressed the role of cognition. However, cognitive theories of meaning in discourse have been neglected by mainstream approaches to CDA, including the sociocognitive approach. Indeed, Wodak (2006: 179) suggests that cognitive theories have been rejected and excluded from CDA by many scholars out of often unjustified reasons. And Chilton (2005a: 21) states that Cognitive Linguistics, which is centrally concerned with meaning, has been eschewed by CDA and does not feature in the literature in any seriously comprehended way.

Within the socio-cognitive approach to CDA, discourse and social structure are mediated by social cognition. According to van Dijk (1993: 280):

It is theoretically essential to understand that there is no other way to relate macrolevel notions such as group dominance and inequality with microlevel notions as text, talk, meaning and understanding. Indeed, the crucial notion of reproduction, needed to explain how discourse plays a 
role in the reproduction of dominance, presupposes an account that relates discourse structures to social cognitions, and social cognitions to social structures.

Such a model may be diagrammatically represented as in figure 1, where the bidirectional arrows denote the dialectical relation between discourse and social structure and the shaded area indicates the microlevel focus of CDA:

Figure 1. Discourse-cognition-society triangle

\section{Social Cognition}

\section{Discourse}

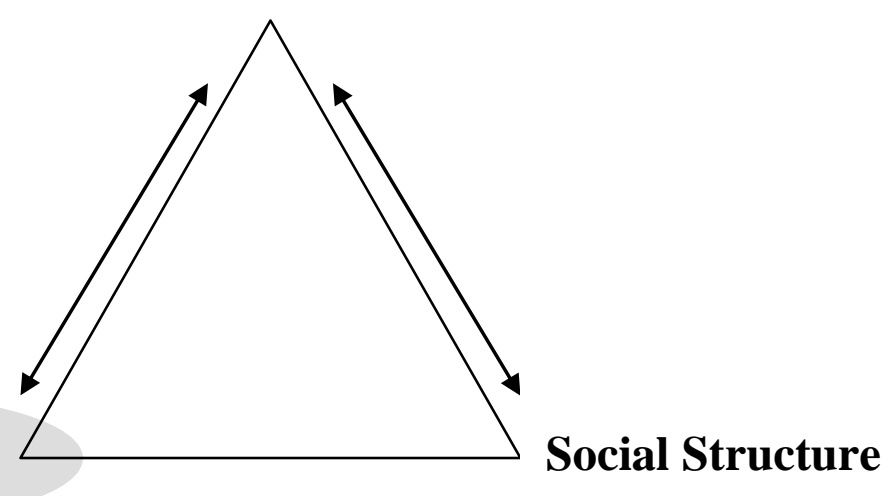

At the microlevel, Cognitive Linguistics provides an apparatus with which metaphor can be addressed in CDA. In attending to metaphor in CDA, Cognitive Linguistics is indeed the perfect tool. Broadly speaking, Cognitive Linguistics, like socio-cognitive CDA, explores the relation between language, cognition, and culture. Furthermore, Cognitive Linguistics provides insights into the pervasiveness and persuasiveness of metaphor.

Available for appropriation in CDA, two accounts of metaphor exist within Cognitive Linguistics: conceptual metaphor theory (Lakoff and Johnson 1981, 1999; Lakoff 1993) and the more recent conceptual blending theory (Fauconnier and Turner 2002). ${ }^{2}$ Whilst conceptual metaphor theory (CMT) and conceptual blending theory (BT) share much in common in their treatment of linguistic and conceptual structure, there are some subtle but important distinctions between them. On the similarities and differences between the two theories, Grady et al. (1999: 101) assert:

Both approaches treat metaphor as a conceptual rather than a purely linguistic phenomenon; both involve systematic projection of language, imagery and inferential structure between conceptual domains . . . However, there are also important differences between the approaches: CMT posits relationships between pairs of mental representations while [BT] allows for more than two; CMT has defined metaphor as a strictly directional phenomenon, while BT has not.

\footnotetext{
${ }^{2}$ It should be noted that conceptual blending theory accounts for a range of linguistic and conceptual phenomena.
} 
Within Cognitive Linguistics, CMT and BT have been treated as both complementary (Grady et al. 1999) and competing (Coulson 2000). They shall be treated here as competing. By far the most prominent, CMT has been applied outside (explicit) CDA in critical metaphor studies across a range of discourses (Beer and De Landtsheer 2004; Chilton 1996; Chilton and Lakoff 1995; Lakoff 1991, 1996, 2003; Santa Ana 2002). CMT and CDA, however, can be said to suffer a number of theoretical tensions or inconsistencies, which is not the case for BT and CDA. Let us now turn to examine the compatibility problems between CMT and CDA, before outlining the alternative, BT. We may term them the problem of focus, the problem of motivation, and the problem of relation. Whilst we may separate them for the purpose of illumination, it should be noted that they are closely intertwined.

\section{Conceptual metaphor theory and CDA: Compatibility problems}

\section{Problem of focus}

CMT is primarily concerned with the conceptual structures from which language is held to naturally arise. Writing within a CMT framework, Santa Ana (2002: 29) states that:

the cognitivist focus of attention is not on individual sentences. The object is not any particular linguistic expression of metaphor, but the metaphoric mapping between two semantic domains.

Consequently, the data CMT presents as evidence for conventionalised conceptual metaphors is often not attested but rather appeals to native speaker intuition. ${ }^{3}$ This is in contrast to CDA, where the focus is on microlevel analysis of concrete examples of discourse, which is to say, actual instances of talk or text in different genres.

CMT is concerned with cross-domain mappings in 'everyday' thought and language (Lakoff and Johnson 1980, 1999). That is, with the way we represent apolitical domains such as time in conceptual and linguistic structure. ${ }^{4}$ CDA, on the other hand, is concerned with discourse on topics which explicitly fall within the social and political realm. Here we may make a Saussurian distinction between language (langue) and discourse (parole), where langue refers to a language system and parole refers to the use of that system for communicative purposes. Discourse, in line with Habermas, is often vested with interests. Is metaphor, then, a matter of language or discourse? Or as Chilton (1996: 65) enquires:

Since the time of Aristotle, discussion of metaphor has oscillated between the cognitive perspective and the oratorical perspective. Sometimes the

\footnotetext{
${ }^{3}$ This is despite the opposition of Cognitive Linguistics to Generative Linguistics in which native speaker intuition is an important kind of evidence.

${ }^{4}$ It should be noted that Goatly (2007) argues for the hidden ideology of such 'everyday' metaphors, including TIME IS SPACE.
} 
two perspectives have been merged. Is metaphor a means of knowledge? .

.. Or is it to do with persuasion and affect?

Of course, metaphor may be a feature of both language and discourse. A CDA perspective, however, requires a theory that allows for metaphor to be treated as discourse. ${ }^{5}$ Herein lays a major contradiction between CMT and CDA, for CMT tends only to focus on the cognitive dimensions of metaphor, maintaining that it is a matter of language and knowledge. ${ }^{6}$ BT, on the other hand, accounts for the cognitive operations involved in the discourse process and thus provides a more suitable apparatus for metaphor in CDA.

\section{Problem of motivation}

Intrinsically tied to CMT is the theory of experientialism or conceptual embodiment (Johnson 1987; Lakoff and Johnson 1980, 1999), which holds that our conceptual structure is directly grounded in the kind of bodies we have and the kind of experiences we have with them and the physical world we inhabit.

For CMT, metaphors, which take the form of an asymmetrical mapping from a source domain onto a target domain, are not arbitrarily constructed. On the contrary, the kinds of knowledge domains which feature as source domains and the kinds which feature as target domains follow a predictable pattern. Source domains, Chilton (2005b: 6) states, "have a clear tendency to be based in human physiological experience". Target domains, on the other hand, "tend to be more abstract, understructured or problematic conceptual areas" (Chilton 2005b: 7). Sensorimotor experiences are said to often provide source domains for subjective experiences. Primary metaphors ${ }^{7}$ are motivated by universal cooccurrences of these two different kinds of experience (Lakoff and Johnson 1999).

CMT constitutes a theory of cognitive semantics, then, which explains the motivation for particular mappings as grounded in experientialist connections between domains, leaving no room for speaker intention. According to Lakoff and Johnson (1999: 56), "primary metaphors are part of the cognitive unconscious". The experientialist commitment of CMT, however, causes theoretical tension with CDA, for which "metaphors are . . . chosen by speakers to achieve particular communication goals within particular contexts rather than being predetermined by bodily experience" (Charteris-Black 2004: 247). If we consider, for example, the metaphorical conceptualisation in immigration discourse of the movement of people as the movement of water (Charteris-Black 2006; Santa Ana 2002), we would not want to claim that this metaphor is grounded in experientialist connections between the domains of water and immigration but rather that the use of this

\footnotetext{
5 The contrast between CMT and CDA, the distinction between language and discourse, reflects the separation in linguistics of semantics and pragmatics respectively. Both semantics and pragmatics are concerned with meaning. They differ, however, in so far as the latter is concerned with speaker intentions (Grice 1975, 1978; Sperber and Wilson 1995). We may characterise semantics as the study of language and pragmatics as the study of discourse.

${ }^{6}$ This is not to say that this knowledge is transcendental. CMT explicitly rejects objectivist epistemology.

${ }^{7}$ After Grady (1997), Lakoff and Johnson (1999: 50-54) offer a representative list of primary metaphors.
} 
non-primary metaphor is instead motivated by the rhetorical intentions of the speaker. For metaphor in CDA, therefore, a more pragmatic approach to metaphor is required:

One of the limitations of metaphor analysis when the cognitive approach is isolated from the pragmatic one is that the only explanation of metaphor motivation is with reference to an underlying experiential basis. This assumes that metaphor use is an unconscious reflex, whereas a pragmatic view argues that speakers use metaphor to persuade by combining the cognitive and linguistic resources at their disposal.

(Charteris-Black 2004: 11)

Whilst Charteris-Black (2004) attempts to resolve the problem of motivation by combining CMT with pragmatic theory, BT actually offers an inherently cognitivepragmatic approach to metaphor.

\section{Problem of relation}

The problem of relation refers to the opposing perceptions in CMT and CDA of the relation between linguistic representation and conceptual representation. For CMT, linguistic metaphor is conceived of as the surface-level manifestation of underlying conceptual metaphor, as expressed by Lakoff (1993: 203):

Metaphor . . . has come to mean 'a cross-domain mapping in the conceptual system'. The term 'metaphorical expression' refers to a linguistic expression (a word, phrase or sentence) that is the surface realisation of such a cross-domain mapping.

In other words, metaphorical expression emerges from mappings at the conceptual level. Consequently, conceptual structure is merely reflected in linguistic structure.

The root of (primary) metaphor according to CMT, then, is conceptual structure, which in turn, is grounded in pre-linguistic bodily experience. In this sense, for CMT, linguistic representation is a product of conceptual representation. This view, however, is inconsonant with CDA, which would maintain the inverse; that linguistic representation in discourse can determine, to some extent, conceptual representation. Importantly for metaphor in CDA, then, a theory is required in which the root of metaphor (in discourse on social and political topics) may be treated as grounded in discourse. Resonating with this perspective, metaphor in BT originates in discourse and then may become embedded at the conceptual level.

A number of compatibility problems between CMT and the CDA perspective have been identified whilst BT, it has been suggested, offers an analytic apparatus more congruent with CDA. Let us now, then, offer an outline of BT. 


\section{Conceptual blending theory}

In contrast to CMT, BT is a theory of online meaning construction. It accounts for some of the conceptual operations performed during discourse. BT is founded upon its precursor, mental space theory (Fauconnier 1994, 1997). In mental space theory, words do not refer directly to entities in the world but rather prompt for the construction of mental spaces, which contain certain elements. According to Fauconnier and Turner (1996: 113):

Mental spaces are small conceptual packets constructed as we think and talk, for purposes of local understanding and action. They are interconnected, and can be modified as thought and discourse unfold.

Elements in a mental space are, inter alia, the entities, objects, actions, and processes referred to explicitly or implicitly in discourse. In any stretch of discourse, a number of interconnected mental spaces may be constructed, where "linguistic expressions will typically establish new spaces, elements within them, and relations holding between the elements" (Fauconnier 1994: 17).

Amongst other phenomena such as reference and metonymy, metaphor is one particular kind of linguistic expression which prompts for the construction of a number of mental spaces. In the case of metaphor, mental spaces constructed during discourse undergo a specific conceptual blending operation ${ }^{8}$ whereby they are manipulated in an integrated network, producing inferential structure. Unlike CMT, in which a mapping occurs across two semantic domains, BT treats metaphor as a conceptual projection involving four mental spaces.

BT adopts a particular diagrammatic notation based in mathematical set theory to represent conceptual blending patterns. The 'basic diagram' is reproduced below, adapted from Fauconnier and Turner (2002: 46):

\footnotetext{
${ }^{8}$ Sometimes referred to as conceptual integration.
} 
Figure 2. Conceptual blending basic diagram

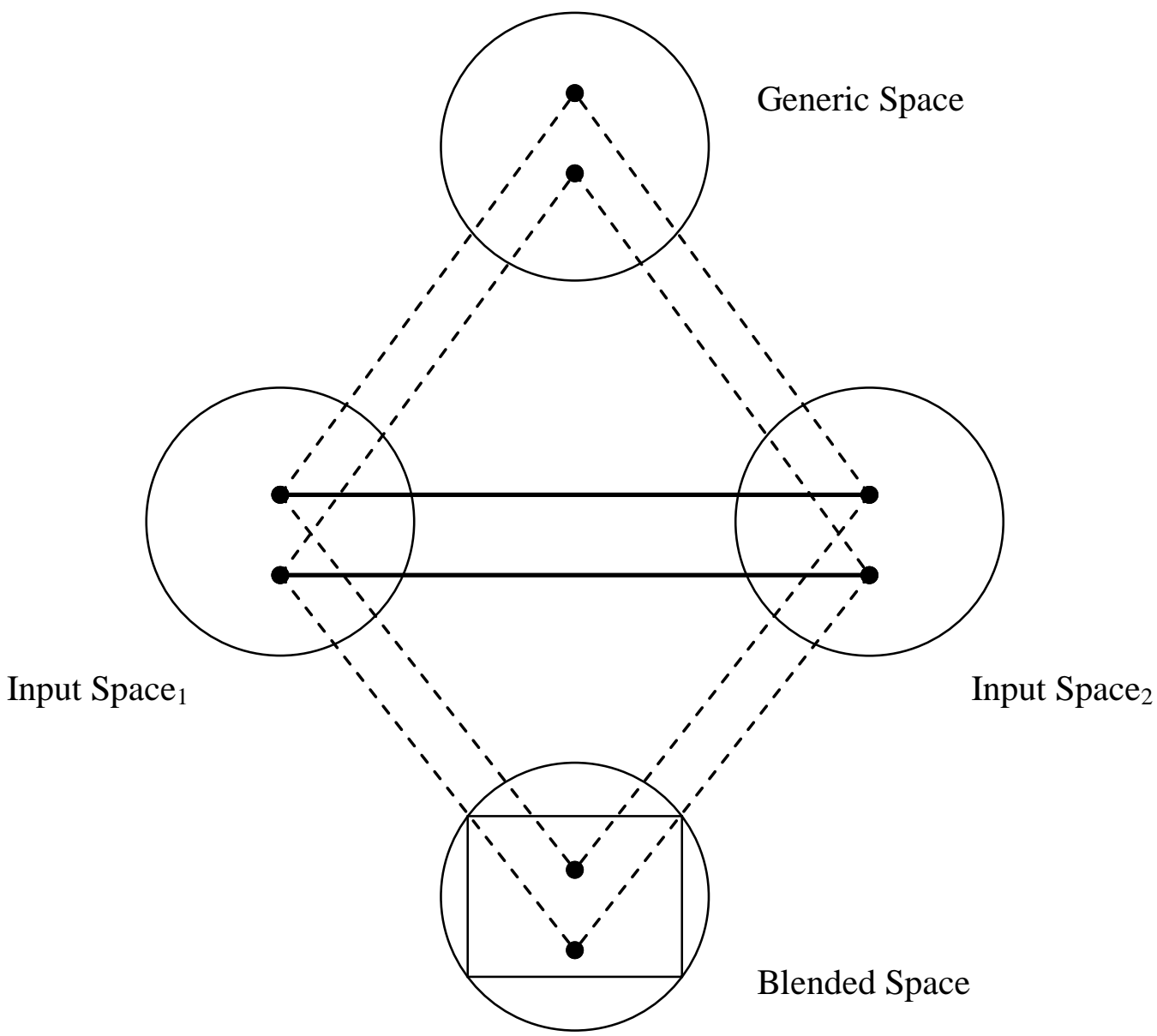

In figure 2 above, the basic diagram of a conceptual blending network, mental spaces are represented by the four large circles. Elements within mental spaces are represented by the points inside the circles. Whilst this diagram is a 'static' illustration of the conceptual blending operation, it is important to recognise, as Fauconnier and Turner (2002: 46) stress, that "such a diagram is really just a snapshot of an imaginative and complicated process".

\section{Input spaces}

Blends arise in networks of mental spaces. The basic blending network consists of four mental spaces: two input spaces, a generic space, and the blended space. ${ }^{9}$ According to Coulson (2000: 23), "a new space is ... set up when utterances concern objects or events that require different background assumptions". Metaphorical utterances in discourse are of precisely this kind; they involve spaces which contain elements belonging to two different (potential) scenarios with different background frames or assumptions. As

${ }^{9}$ Conceptual integration always involves at least these four spaces (Fauconnier and Turner 2002: 279). However, cases of multiple blends exist in which blends themselves can enter into a blending chain, functioning as inputs in further blending networks. 
metaphorical discourse unfolds, then, a space is created for each scenario. These spaces are input space $_{1}$ and input space en $_{2}$ respectively. In conceptual integration, the two input spaces share counterpart connections between elements, represented in the diagram by the solid lines. Counterpart connections can be of many different kinds, generally referred to as vital relations. Fauconnier and Turner (2002: 89-111) identify a number of vital relations including identity, role, intentionality, time, space, and category. The dashed lines connecting the elements inside the four spaces represent conceptual projections across the network. These connective lines correspond to neural coactivations and bindings (Fauconnier and Turner 2002: 46).

\section{Generic space}

In addition to the two input spaces, there is the generic space. The generic space contains abstract structure which is common to the counterpart elements in both of the input spaces. In other words, "at any moment in the construction of the network, the structure that inputs seem to share is captured in a generic space" (Fauconnier and Turner 2002: 47). In turn, elements in the generic space project onto the counterpart elements in the input spaces. We can think of structure in the generic space in terms of thematic roles, categories which structure the linguistic representation in discourse of a given scenario. For example, with regard to who did what to whom where and how.

\section{Blended space}

Finally, the fourth space, the blended space, is arrived at via conceptual blending operations. It receives structure from both the input spaces. In blending, "structure from two input mental spaces is projected to a new space, the blend" (Fauconnier and Turner 2002: 47). The blended space also receives structure from the generic space. "Generic spaces and blended spaces are related: blends contain generic structure captured in the generic space" (Fauconnier and Turner 2002: 47).

\section{Emergent structure}

The most important thing to note in the basic diagram is the box inside the blended space, which represents emergent structure.

In blending, structure from two input spaces is projected to a separate space, the 'blend'. The blend inherits partial structure from the input spaces, and has emergent structure of its own.

(Fauconnier and Turner 1996: 113)

Emergent structure is structure unique to the blend. That is, the blended space contains structure which is not copied there directly from the input spaces but which rather is a product of blending operations. Emergent structure is generated by three blending processes: composition; completion; elaboration. 


\section{Composition}

Through composition, the projections in the blending network create new relations in the blended space. In Fauconnier and Turner's (2002: 48) words, "blending can compose elements from the input spaces to provide relations that do not exist in the separate inputs". Counterpart elements can be composed to produce two separate elements in the blended space. However, in the case of metaphor, a special kind of composition occurs, referred to as fusion. Here, counterpart elements in the input spaces get projected into the blended space, creating a single compound element. ${ }^{10}$ It is important to note that the relation, or topology, between counterpart elements is maintained in the blend.

\section{Completion}

Completion occurs as relevant structure from background knowledge associated with the elements in the input spaces is recruited into the blend. Such background knowledge may take the form of contextual information or conceptual frames, for example. According to Fauconnier and Turner (2002: 48):

We rarely realise the extent of background knowledge and structure that we bring into a blend unconsciously. Blends recruit great ranges of such meaning ... We see some parts of a familiar frame of meaning, and much more of the frame is recruited silently but effectively to the blend.

A conceptual frame is a cognitive-based, stable but modifiable knowledge structure for given scenes or scenarios stored in long-term memory. ${ }^{11}$ According to Fillmore (1985: 224), "a frame represents the particular organisation of knowledge which stands as a prerequisite to our ability to understand the meanings of . . associated words". It is in this sense, then, that "mental spaces operate in working memory but are built up partly by activating structures available from long-term memory" (Fauconnier and Turner 2002: 102). Frames are activated by discourse and at the same time provide background information which gives meaning to discourse. In BT terms, elements in input spaces activate the wider conceptual frames to which they belong, relevant structure from which may in turn be recruited into the blended space via the process of completion. It should be noted that not all available structure from conceptual frames necessarily gets projected into the blended space, only that which is relevant to the speaker's intention in constructing the blend. This is known as selective projection and is guided by normal pragmatic constraints.

Selective projection in conceptual blending further contributes to the ideology of metaphor. Elements available for recruitment may not get projected into the blended space. Where selective projection in conceptual blending networks is a pragmatic phenomenon, integration networks are constructed according to speakers' communicative

\footnotetext{
${ }^{10}$ The basic diagram in figure 2 has been adapted from Fauconnier and Turner (2002: 46) to show both counterpart elements being fused in the blended space.

${ }^{11}$ Referred to elsewhere as script (Schank and Abelson 1977) or idealised cognitive model (Lakoff 1987).
} 
(and rhetorical) intentions. In other words, ideologically, speakers may choose to recruit particular structure in order to promote a certain perceived reality. ${ }^{12}$

\section{Elaboration and the blended space}

Elaboration is the most significant stage in the blending process. ${ }^{13}$ It is the 'running of the blend'. Fauconnier (1997: 151) states that elaboration "consists in cognitive work performed within the blend, according to its own emergent logic". Herein lays the importance of conceptual blending for CDA. As a function of emergent structure in the blended space, metaphor is 'cognitively real'. Moreover, metaphor in discourse thus has absolute consequences for further cognitive processes: "blended spaces are sites for central cognitive work: reasoning . . ., drawing inferences . . ., and developing emotions" (Fauconnier and Turner 1996: 115).

\section{Conceptual blending theory and CDA}

Socio-cognitive CDA maintains that discourse occurs in short-term memory (STM) against knowledge stored in long-term memory (LTM) (van Dijk 2002). Similarly, conceptual blending is a cognitive operation performed in STM, or working memory, online as discourse unfolds, against structures in LTM such as conceptual frames, elements from which may be recruited in the blending process. Blending networks themselves, though, can become embedded in LTM through a process of entrenchment:

Mental spaces are built up dynamically in working memory, but they can also become entrenched in long-term memory ... entrenchment is a general possibility not just for individual mental spaces but for networks of spaces. In particular, integration networks built up dynamically can become entrenched and available to be activated all at once.

(Fauconnier and Turner 2002: 103)

Within the socio-cognitive framework, LTM is further broken down into episodic and semantic (or social) memory (van Dijk 2002). Social cognitions, which are social "because they are shared and presupposed by group members" (van Dijk 1993: 257), reside in semantic memory. Entrenched blends will likewise comprise part of semantic memory, given their socially shared nature:

Blends themselves can also become entrenched.. . giving rise to conceptual and formal structures shared throughout the community. ${ }^{14}$

(Fauconnier and Turner 2002: 49)

\footnotetext{
12 The 'choice' that speakers make in selective projection need not necessarily be a conscious one but may be more intuitive, guided by a rhetorical or ideological intention.

${ }^{13}$ It is important to note that, although it is convenient to present it as such, elaboration is not a final stage in the blending process. Conceptual blending is a kind of parallel rather than serial processing.

${ }^{14}$ For BT, this 'community' is a language community. Applied in CDA, though, this 'community' can be thought of more in terms of a discourse community.
} 
Since social cognition is defined as "the system of mental representations and processes of group members" (van Dijk 1995: 18), we may characterise entrenched blends as social cognitions in one particular form. Entrenched conceptual blending networks are precisely mental representations and processes of group members. Furthermore, where social inequality is facilitated through the reproduction of social cognition, entrenchment is reproduction. Accordingly, where the relation between discourse, cognition and social structure may be diagrammatically represented as in figure 1, we may offer a corresponding model specifically for metaphor in CDA as follows in figure 3 :

Figure 3. Metaphor in the discourse-cognition-society triangle

\section{Entrenched Blends}

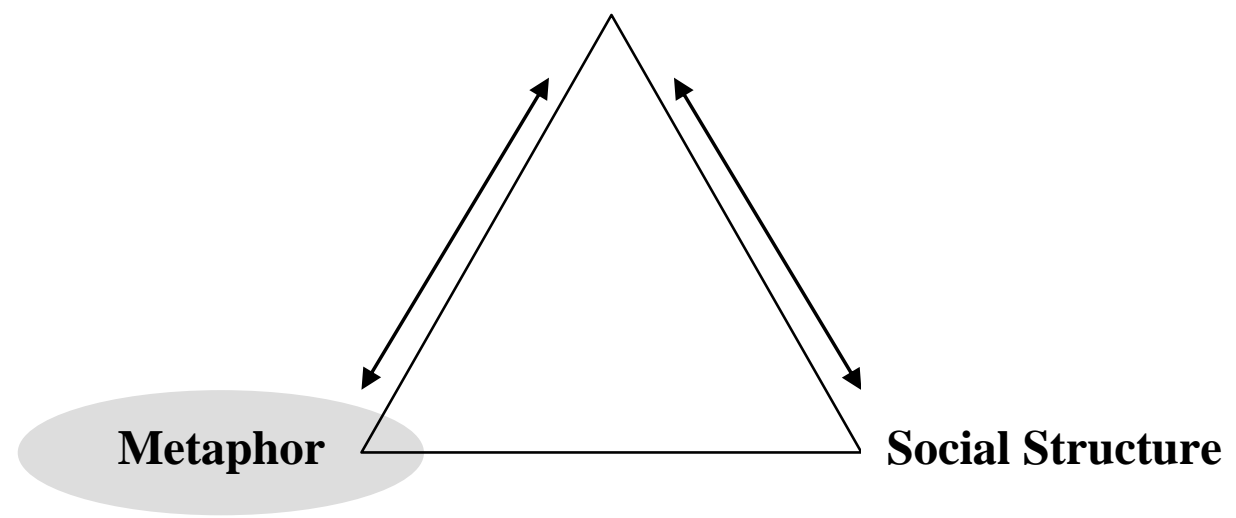

In contrast to CMT, then, BT is entirely resonant with the dialectical relation perceived by CDA between discourse and social structure. As discourse can be constitutive of social structure, mediated by social cognition, so metaphor in discourse can be constitutive of social structure, mediated by entrenched conceptual blends.

Not all blending networks, though, are or become entrenched. So the questions then arise - Which blending networks are entrenched and what is the evidence that these blending networks are entrenched? To answers these questions we must draw on several different concepts of discourse. Hopefully, this will also enable us to reconcile the socialconstructivist perspective of CDA with the cognitive-individualism of BT.

So far, we have tended to use the term discourse in the concrete sense that it is traditionally used in linguistics - to refer to particular instances of talk or text situated in time and place. ${ }^{15}$ However, Foucault uses discourse more abstractly to refer to "a regulated practice that accounts for a number of statements" (1972: 80). It is this concept of discourse which inspires Kress' (1985: 6-7), when he states: "a discourse provides a set of possible statements about a given area, and organises and gives structure to the manner in which a particular topic, object, process is to be talked about." Foucault alternatively uses the terms in a collective sense to refer to "an individualisable group of statements" (1972: 80). Inspired by this definition, Fairclough applies the concept of

\footnotetext{
${ }^{15}$ Talk and text can be considered spoken and written forms of discourse in this concrete sense.
} 
order of discourse, where "the order of discourse of some social domain is the totality of its discursive practices" (Fairclough 1995: 132).

The important point here is the relation between these concepts of discourse. Discourse (abstract) dictates the nature of discourse (concrete) and therefore discourses (collective), where a discourse (collective) is the sum of discourse (concrete). But at the same time, it is from discourse (concrete) and discourses (collective) that discourses (abstract) come in to being. Of course, according to CDA's macrolevel social critique, it is from elite discourse (concrete) and discourses (collective) that discourses (abstract) arise.

How, then, do metaphors and the conceptual blending patterns they prompt for fit within this system? Metaphors, which occur in discourse (concrete), can be more or less conventional. When a particular metaphor is used conventionally we can say that it consists as part of a discourse (collective). Conventional uses of metaphor reflect entrenched conceptual blending networks. With this statement we must be careful not to think that the problem of relation must also apply here. Synchronically, current conventional uses of metaphor reflect entrenched conceptual blending patterns. But conventionalisation is of course a diachronic sociolinguistic process. Diachronically, conventional uses of metaphor give rise to entrenched conceptual blending patterns. Entrenched conceptual blending networks, then, are discourses (abstract). It is not inconsistent to characterise entrenched conceptual blending patterns as both social cognitions and discourses (abstract), where according to Weiss and Wodak (2003: 13) "the discourse-historical approach [to CDA] elaborates and links to the sociocognitive theory of van Dijk . . . and views 'discourse' as a form of knowledge and memory".

After a highly theoretical discussion, let us now see how the framework developed here may be applied. For the purpose of illustration, we will examine the metaphorical constructions of nation, immigration and immigrants in a genre where persuasion is certainly a major communicative goal of the speaker, the election manifesto (CharterisBlack 2004). More specifically, part of the 2005 general election manifesto of the British National Party (BNP) will be the subject of investigation. ${ }^{16}$ Whilst the BNP are a fringe party located on the extreme right of the political spectrum, recently they have enjoyed unprecedented media attention and have achieved record results in both general and local elections. In the 2005 general election, they won a total of 192,746 votes, an increase of over $300 \%$ on their performance in the previous 2001 election. In the 2006 local elections, the BNP more than doubled its number of councillors, increasing the number from 20 to $52 .^{17}$

\footnotetext{
${ }^{16}$ The full text is available at http://www.bnp.org.uk/candidates2005/man_menu.htm. Examples are taken from the subsection entitled Immigration: a crisis without parallel. Accessed 20/10/2006

${ }^{17}$ Information sourced from http://en.wikipedia.org/wiki/British_National_Party. Accessed 20/10/2006
} 


\section{Metaphor and blending in right-wing discourse}

CDA views discourse structures as linguistic representation formulated in order to achieve certain strategies. ${ }^{18}$ Referential and evaluative strategies have been identified as particularly important in racist discourse. Referential strategies are used in discourse to represent/construct social actors (participants) in a given scenario. Typically, this involves the construction and polarisation of an in-group versus an out-group. Such a strategy is achieved linguistically through categorization, for example, in the form of ethnonyms and toponyms. However, it is also achievable with the use of metaphor. Presupposing a referential strategy, an evaluative strategy is manifested in the negative representation of the out-group. Evaluative strategies may be achieved with various standard arguments, for example, the topoi of danger, number, or displacement (Wodak and Sedlak 2000: 233). Metaphor also can function as a standard argument realising an evaluative strategy.

In the opening paragraph of the BNP text, immigration is presented metaphorically as a threat. Furthermore, a metonymy is constructed in which immigration and terrorism are linked. This construction is an example of the topos of danger:

\section{Paragraph 1}

Britain's very existence today is threatened by immigration. As a nation we must rebuild trust in the immigration system amongst the British electorate whilst simultaneously ensuring that National Security is maintained in the era of global terrorism.

In paragraph 2, the movement of people is presented metaphorically as a 'flood of asylum seekers':

Paragraph 2

If Tony Blair can say that it is "neither racist nor extremist" to raise "genuine concerns" about the flood of asylum seekers, then it is no longer feasible to pretend the crisis doesn't exist.

This metaphorical structure clearly realises an evaluative strategy with a topos of danger. The use of 'flood' may also be considered a topos of number, where a flood involves particularly large quantities of water. According to Wodak and Sedlak (2000: 233):

Immigrants or refugees are typically said to come in large numbers, which results in the conclusion that immigration must be reduced or even stopped. An argumentation schema like this one is defined as topos of number.

\footnotetext{
${ }^{18}$ Note that strategy here refers to speaker strategy. If we adopt CMT, due to the problem of motivation, it is not possible to conceive of metaphor as serving a strategic function.
} 
If we consider how a blending network for 'flood of asylum seekers' might be constructed, as in figure 4, further ideological consequences of this construction can be observed.

Figure 4. Conceptual blending network for 'flood of asylum seekers'

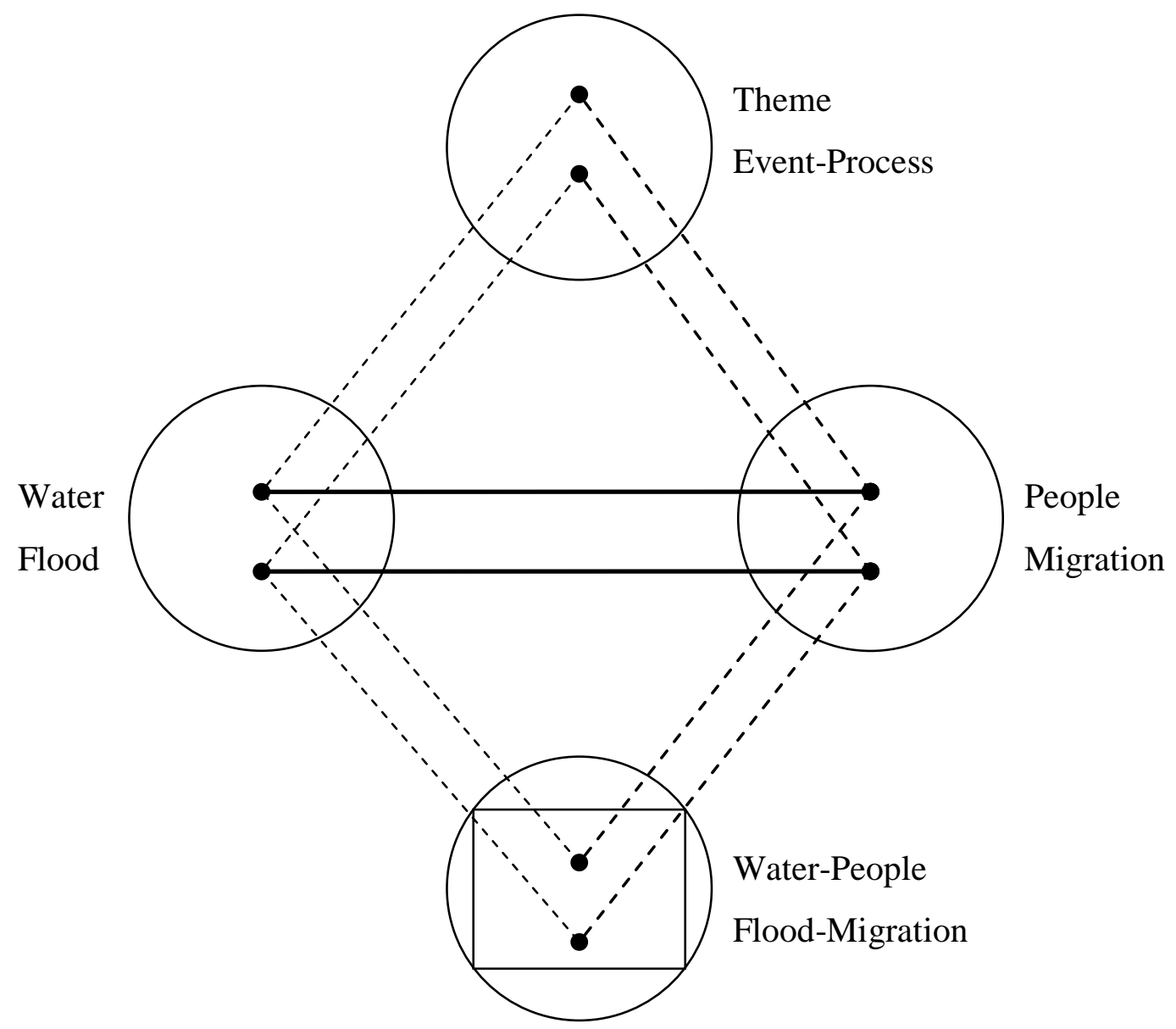

Here, prompted by "flood" and "asylum seekers", two mental spaces are constructed which enter into a conceptual integration network. Emergent structure arises in the blended space in which the two counter-part elements in each input space are fused through composition. The blending process, then, produces emergent structure in which the migration of people is conceptualised as a flood of water. Notice here that a flood is an event whereas migration is a (demographic) process. Events and processes are closely related, where events are often the consequence of processes. This relation is captured in the generic space. In the blended space, emergent structure arises in which immigration is conceptualised as an ongoing event, or an event-process. This conceptualisation is only possible through the juxtaposition of the two input spaces, and cannot be accounted for by the asymmetrical mapping in the CMT model. Importantly, the kinds of action one is likely to take during a flood is different to that which one would take after the event. The conceptualisation of an ongoing 'flood of asylum seekers' immediately warrants the implementation of restrictive immigration policy in order to stop the 'flood'. 
Whilst the themes water and people are both entities of some kind, they are different kinds of entities. Note that part of knowledge stored in the conceptual frame for water, activated by the water element in input space $_{1}$, includes the fact that it is a mass noun such that the movement of water is conceptualised as the movement of a single entity. When projected into the blended space, this knowledge will produce emergent structure in which the migration of people is also conceptualised as a single moving entity. The configuration of such a network has a number of significant consequences after elaboration. The migration of people conceptualised as a single moving entity masks the plight of individual immigrants. It carries the inference that immigration is a simple phenomenon and makes available the inference that all cases may be treated in the same way. On the ideology of examples such as these, Santa Ana (2002: 72) states:

To characterise the movement of people as moving water might seem quite natural, but such a formulation of movement of people is not the only possible image that can be employed.

Also ideologically, notice that structure available for recruitment from the general water frame, such as its importance in sustaining life, does not get projected into the blended space.

In a similar example, immigration is not presented as a 'flood of water' but less intensely as a 'flow of water':

Paragraph 19

A BNP government would accept no further immigration from any of the parts of the world which present the prospect of an almost limitless flow of immigration.

This metaphor will give rise to much of the same inferential structure as the previous example, derived from the conceptual frame for water. This example is particularly interesting, though, when one considers it in conjunction with a preceding metaphor in which Britain is conceptualised as a container:

Paragraph 15

Britain is full up and the government of Britain has as its first responsibility the welfare, security and long-term preservation of the native people of Britain.

The cohesive interaction of these two metaphors may produce a blending network as below in figure 5. Emergent structure arises in the blended space in which the three counter-part elements in each input space are fused through composition. The blending process, then, produces emergent structure in which the nation is conceptualised as a container and the migration of people as the flowing of water into the container. Stored in one's conceptual frame for containers is the fact that they have a limited capacity. Where hearers are prompted to conceptualise immigration to Britain as the flowing of water into a container already at its capacity, elaboration of such a network makes available the inference that Britain could 'overflow', an inference which again immediately justifies restrictive immigration policy. 
Figure 5. Conceptual blending network for interaction of 'flow of immigration' and 'Britain is full up'

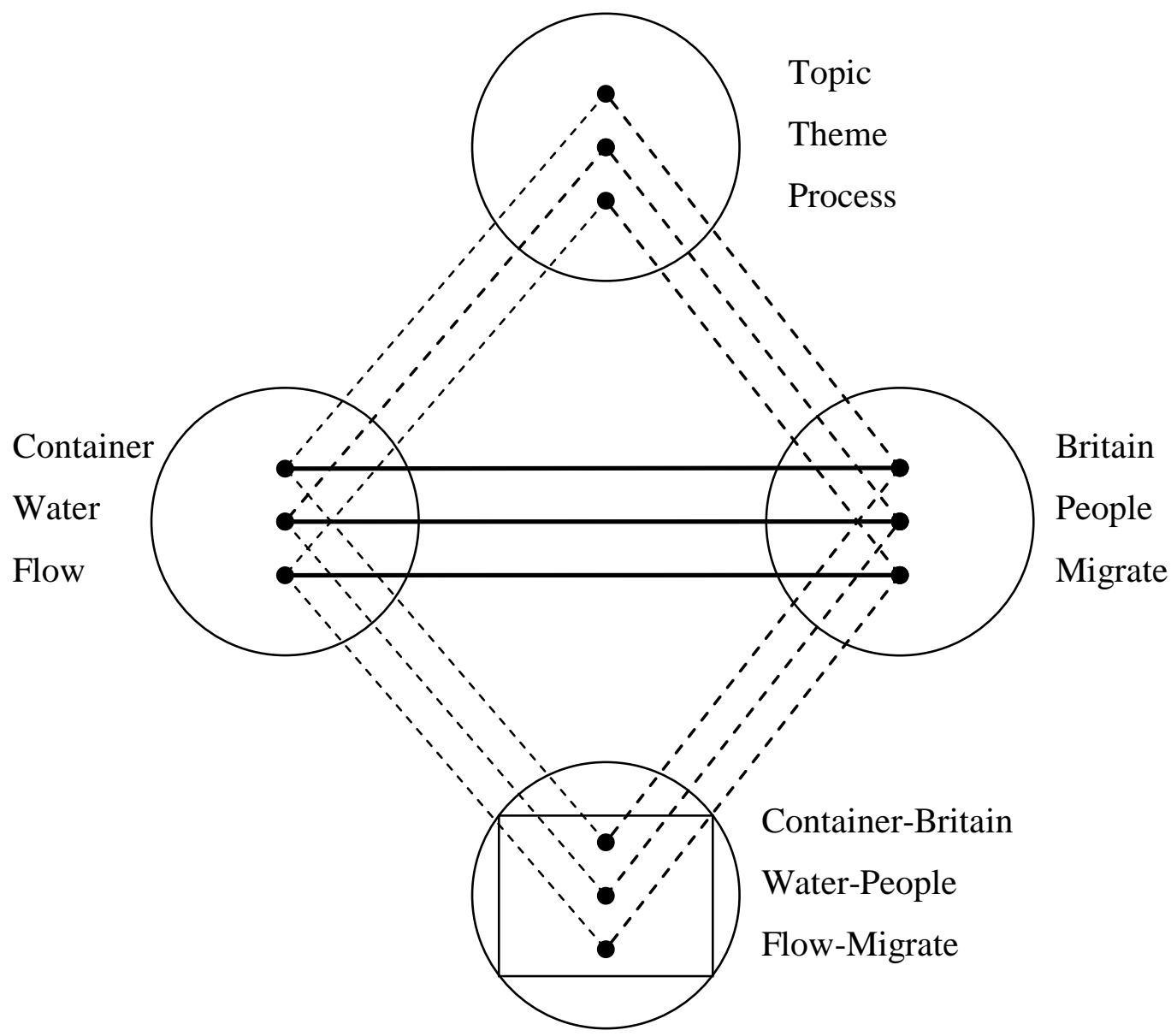

Notice also in the example from paragraph 15 the phrase "long-term preservation of the native people of Britain". Against a blending network such as that in figure 5, this construction may be realising a topos of displacement, promoting the image of the native British population becoming 'diluted' by immigration.

An alternative construction of the nation which is particularly significant in immigration discourse involves metaphors whereby the nation is conceptualised as a house (Chilton 1994). Consider the following examples:

Paragraph 7

Every nation, no matter how open or closed its immigration policy may be, has the right and duty to maintain sovereign physical control of its borders.

Paragraph 19

Our first step will be to shut the door.

When these two metaphors interact cohesively, a blending network such as follows in figure 6 may arise. 
In this blending network, emergent structure arises in the blended space where the counter-part elements of house and nation converge. Immigration policy and door also become fused. And to shut the door becomes fused with implementing restrictive immigration policy, both actions as captured in the generic space.

Figure 6. Conceptual blending network for interaction of 'open or closed its immigration policy' and 'shut the door'

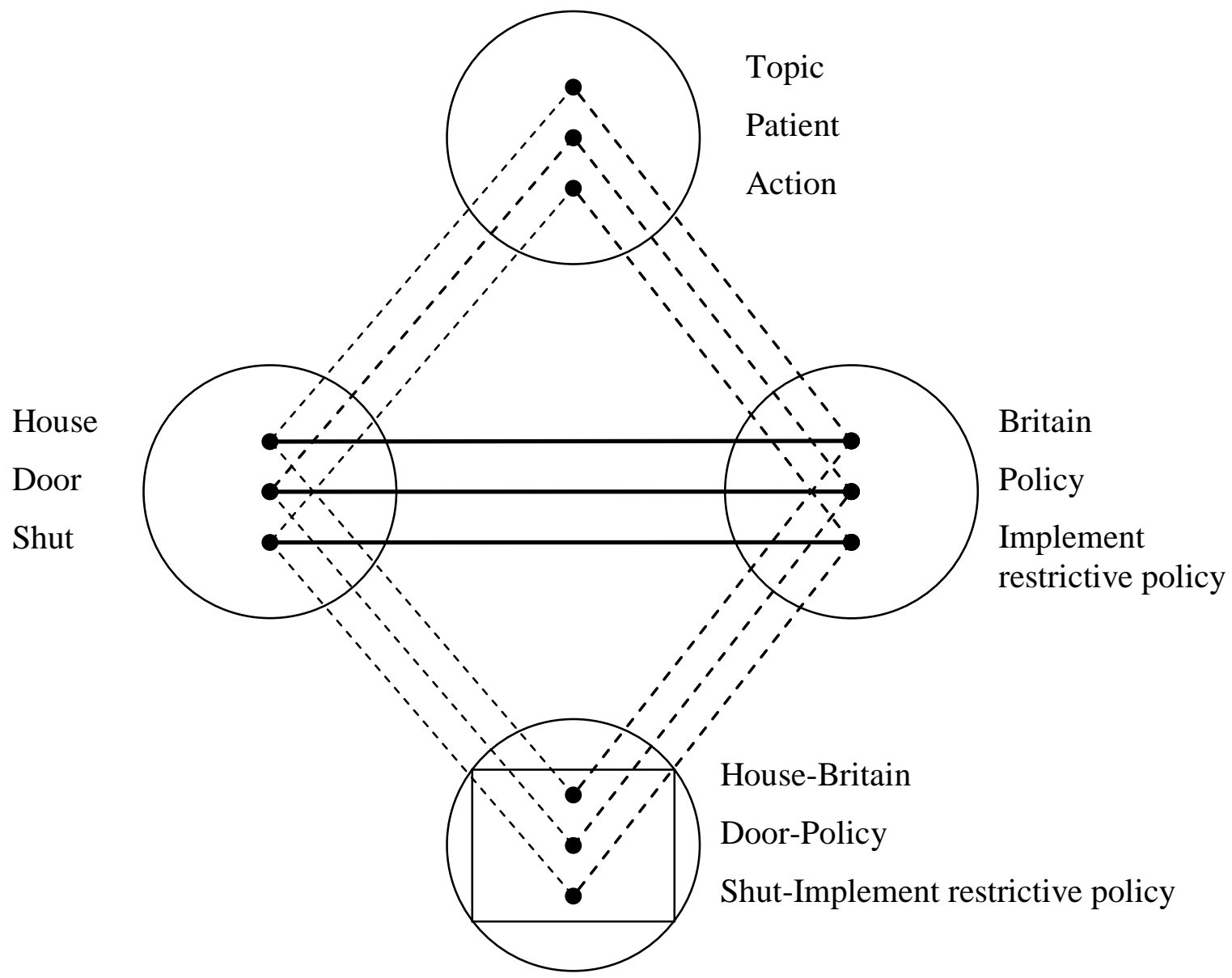

Now, part of knowledge stored in the conceptual frame for house is that it is a private dwelling, entry into which is only at the permission of the resident. Within the blended space of this integration network, then, the nation is conceptualised as a private property, where policy makers have the right to refuse entry to certain individuals. Recalling that the blended space is not only the site of reasoning but also for developing emotions, elaboration of a network where house and nation provide counter-part elements may elicit emotional responses that have to do with violation of personal space. This is especially reinforced in the following example:

Paragraph 7

We ... shall continue to increase budget and personnel until our borders are secure against significant intrusion. 
Abstractable from any kind of container, including a house, is a container schema. Image schemas are dynamic cognitive constructs which "represent schematic patterns arising from imagistic domains" (Croft and Cruse 2004: 44). The container schema has been observed to feature in the metaphorical construction of the nation across various discourses, including immigration discourse (Charteris-Black 2006; Chilton 1994).

A container schema has an inherent 'logic' or topology consisting of three salient structures: an interior and exterior defined by a boundary. In immigration discourse, this structure can get projected into the blended space, giving rise to emergent structure in which the nation is conceptualised with the same topology. The container schema affords two perspectives: vantage-point-interior and vantage-point-exterior. As a function both of the topology of the container schema and the vantage-point-interior perspective always adopted in immigration discourse, the container schema denotes insiders versus outsiders. Consequently, any metaphor in immigration discourse involving a container may realise a referential strategy. ${ }^{19}$

\section{Conclusion: Further constructing the theoretical framework}

This paper has attempted to develop a theoretical framework by which metaphor may be addressed in explicit CDA. Conceptual blending theory rather than conceptual metaphor theory has provided the apparatus for microlevel analysis. Where entrenchment is the reproduction of social cognition in one form, conceptual blending theory has been shown to fit within the socio-cognitive approach to CDA in particular. This framework has then been applied in a qualitative analysis of metaphor in a single text. However, since entrenchment depends in part on conventionality of usage, a complete and lucid framework requires quantitative analysis across different discourse genres in order to determine which metaphors are used conventionally in a given discourse and, by implication, which blending networks are most likely to be(come) entrenched.

\footnotetext{
${ }^{19}$ Appropriating Chilton's (2004) discourse space theory in which referents are conceptualised as located in a discourse space consisting of three intersecting axes, Hart (2006) demonstrates that metaphors in immigration discourse where a container and nation provide counter-part elements in an integration network may realise an evaluative strategy as a function of the 'distance' at which they prompt for the outgroup to be positioned along the modal (or evaluative) axis.
} 


\section{References}

Beer, F. A. and De Landtsheer, C. (Eds.) (2004). Metaphorical world politics. East Lansing: Michigan State University Press.

Charteris-Black, J. (2004). Corpus approaches to critical metaphor analysis. Basingstoke: Palgrave Macmillan.

Charteris-Black, J. (2006). Britain as a container: immigration metaphors in the 2006 election campaign. Discourse and Society, 17, 563-581

Chilton, P. (1994). "La plaie qu'il convent de fermer...": les metaphors du discourse raciste. Journal of Pragmatics, 21, 583-619.

Chilton, P. (1996). Security metaphors: Cold war discourse from containment to common house. New York: Peter Lang.

Chilton, P. (2004). Analysing political discourse: Theory and practice. London: Routledge.

Chilton, P. (2005a). Missing links in mainstream CDA: modules, blends and the critical instinct. In R. Wodak and P.Chilton (Eds.). A New Agenda in (Critical) Discourse Analysis. Amsterdam: John Benjamins. PAGES 19-52.

Chilton, P. (2005b). Manipulation, memes and metaphors: the case of Mein Kampf. In L. D. Saussure and P. Schulz (Eds.). Manipulation and Ideologies in the Twentieth Century. Amsterdam: John Benjamins. PAGES 15-44.

Chilton, P. and Lakoff, G. (1995). Foreign policy by metaphor. In C. Schaffner and A. Wenden (Eds.). Language and Peace. Aldershot: Ashgate. PAGES 37-60.

Chilton, P. and Schäffner, C. (2002). Themes and principles in the analysis of political discourse. In P. Chilton and C. Schäffner (Eds.). Politics as Text and Talk. Amsterdam: John Benjamins. PAGES 1-44.

Coulson, S. (2000). Semantic leaps: Frame-shifting and conceptual blending in meaning construction. Cambridge: Cambridge University Press.

Croft, W. and Cruse, D. (2004). Cognitive linguistics. Cambridge: Cambridge University Press.

Fairclough, N. (1989). Language and power. Harlow: Longman.

Fairclough, N. (1995). Media discourse. London: Edward Arnold.

Fauconnier, G. (1994). Mental spaces: Aspects of meaning construction in natural language. Cambridge: Cambridge University Press.

Fauconnier, G. (1997). Mappings in thought and language. Cambridge: Cambridge University Press.

Fauconnier, G. and Turner, M. (1996). Blending as a central process of grammar. In E. Goldberg Adele (ed.). Conceptual Structure, Discourse and Language. Stanford, California: CSLI Publications. PAGES 113-130.

Fauconnier, G. and Turner, M. (2002). The way we think: Conceptual blending and the mind's hidden complexities. New York: Basic Books.

Fillmore, C. (1985). Frames and the semantics of understanding. Quaderni Di Semantica, VI (2), 222-254.

Foucault, M. (1972). The Archaeology of Knowledge. Trans. A.M. Sheridan Smith. London: Routledge. 
Fowler, R. (1991). Language in the news: Discourse and ideology in the British press. London: Routledge.

Fowler, R., Hodge, R., Kress, G. and Trew, T. (1979). Language and control. London: Routledge and Kegan Paul.

Goatly, A. (2007). Washing the brain: The hidden ideology of metaphor. Amsterdam: John Benjamins.

Grady, J. (1997). Foundations of meaning: Primary metaphors and primary scenes. $\mathrm{PhD}$ Thesis. University of California, Berkely.

Grady, J., Oakley, T. and Coulson, S. (1999). Blending and metaphor. In G. Steen and R. Gibbs (Eds.). Metaphor in Cognitive Linguistics. Philadelphia: John Benjamins. PAGES 101-124.

Grice, H. P. (1975). Logic and conversation. In P. Cole and J. L. Morgan (Eds.). Syntax and Semantics 3: Speech Acts. New York: Academic Press. PAGES 41-58.

Grice, H. P. (1978). Further notes on logic and conversation. In P. Cole (Eds.). Syntax and Semantics 9: Pragmatics. New York: Academic Press. PAGES 113-128.

Halliday, M.A.K. (1985). An introduction to functional grammar. London: Arnold

Halliday, M.A.K. and Hasan, R. (1985). Language, context, and text: Aspects of language in a social-semiotic perspective. Victoria: Deakin University Press.

Hart, C. (2006). Containers, conceptual blends and discourse space in immigration metaphors: referential and evaluative strategies. Paper presented at First International Conference, Critical Approaches to Discourse Analysis Across Disciplines. Norwich, 29-30 June.

Hodge, R. and Kress, G. (1993). Language as ideology (2nd edition). London: Routledge.

Johnson, M. (1987). The body in the mind: The bodily basis of meaning, imagination and reason. Chicago: University of Chicago Press.

Kress, G. (1985). Linguistic processes in sociocultural practice. Victoria: Deakin University Press.

Kress, G. and Hodge, R. (1979). Language as ideology. London: Routledge and Kegan Paul.

Lakoff, G. (1987). Women, fire, and dangerous things: What categories reveal about the mind. Chicago: University of Chicago Press.

Lakoff, G. (1991). Metaphor in politics: an open letter to the internet by George Lakoff. (URL: http://philosophy.uoregon.edu/metaphor/lakoff-1.htm. Accessed October 20, 2006).

Lakoff, G. (1993). The contemporary theory of metaphor. In A. Ortony (Ed.). Metaphor and thought (2nd edition). Cambridge: Cambridge University Press. PAGES 202-251.

Lakoff, G. (1996). Moral politics: What conservatives know that liberals don't. Chicago: University of Chicago Press.

Lakoff, G. (2003). Metaphor and war again. (URL: http://www.alternet.org/story/15414. Accessed October 20, 2006).

Lakoff, G. and Johnson, M. (1980). Metaphors we live by. Chicago: University of Chicago Press.

Lakoff, G. and Johnson, M. (1999). Philosophy in the flesh: The embodied mind and its challenge to western thought. New York: Basic Books.

Santa Ana, O. (2002). Brown tide rising: Metaphors of Latinos in contemporary American public discourse. Austin: University of Texas Press. 
Schank, R. C. and Abelson, R. P. (1977). Scripts, plans, goals and understanding: An inquiry into human knowledge structures. Hillsdale, NJ: Lawrence Erlbaum Associates.

Sperber, D. and Wilson, D. (1995). Relevance: Communication and cognition (2nd edition). Oxford: Blackwell.

van Dijk, T. A. (1993). Elite discourse and racism. London: Sage Publications.

van Dijk, T. A. (1995). Discourse analysis as ideology analysis. In C. Schaffner and L. W. Anita (Eds.). Language and Peace. Amsterdam: Harwood Academic Publishers. PAGES 17-36.

van Dijk, T. A. (2000). Ideologies, racism, discourse: debates on immigration and ethnic issues. In J. ter Val and M. Verkuyten (Eds.). Comparative Perspectives on Racism. Aldershot: Ashgate. PAGES 91-116.

van Dijk, T. A. (2002). Ideology: political discourse and cognition. In P. Chilton and C. Schäffner (Eds.). Politics as Text and Talk. Amsterdam: John Benjamins. PAGES 203-238.

Wodak, R. (2001). What is CDA about - a summary of its history, important concepts and its developments. In R. Wodak and M. Meyer (Eds.). Methods of critical discourse analysis. London: Sage. PAGES 1-13.

Wodak, R. (2006). Mediation between discourse and society: Assessing cognitive approaches in CDA. Discourse and Society, 8(1), 179-190.

Wodak, R. and Sedlak, M. (2000). "We demand that the foreigners adapt to our lifestyle..." Political discourse on immigration laws in Austria and the United Kingdom. In E. Appelt and M. Jarosch (Eds.). Combating Racial Discrimination. Affirmative action as a model for Europe. Oxford: Berg. PAGES 217-237. 